\title{
Avaliação de segurança em empresas da construção civil: uma aplicação da lógica Fuzzy
}

\author{
ALOISIO CELSO DE ARAUJO ${ }^{1}$ \\ JOÃO ALBERTO NEVES DOS SANTOS ${ }^{1}$ \\ GILSON BRITO ALVES LIMA ${ }^{2}$ \\ JULIO NICHIOKA ${ }^{3}$ \\ LUIZ OCTÁVIO GAVIÃO ${ }^{4}$
}

'Universidade Federal Fluminense (UFF) / Escola de Engenharia, Departamento de Engenharia Civil, Niterói - RJ, Brasil

${ }^{2}$ Universidade Federal Fluminense (UFF) / Escola de Engenharia, Departamento de Engenharia de Produção, Niterói - RJ, Brasil

${ }^{3}$ Universidade do Estado do Rio de Janeiro (UERJ) / Departamento de Engenharia Civil/Escola de Engenharia, Rio de Janeiro - RJ, Brasil

${ }^{4}$ Escola Superior de Guerra (ESG) / Centro de Capacitação em Aquisição de Defesa, Rio de Janeiro - RJ, Brasil

\begin{abstract}
Resumo
A Indústria da Construção (IC) é uma das atividades produtivas de maior perigo para os trabalhadores, especialmente por ocorrência de acidentes de trabalho fatais e não fatais. Estimativas da OIT para o ano de 2012 mostram que são 2,3 milhões de mortes a cada ano, decorrentes de falta de treinamento. Estima-se que, também a cada ano, ocorram pelo menos 60.000 acidentes fatais na IC em todo o mundo, um óbito a cada 10 minutos, sendo um em cada seis acidentes fatais na IC. Este estudo tem por objetivo estabelecer um modelo de mecanismo gerencial de indicadores para a gestão de segurança de empresas de construção civil, baseado em programas nacionais de premiação e modelos de gestão, com aplicação da lógica Fuzzy. O modelo elaborado com base nesta lógica apresenta dimensões e critérios cujos resultados apontaram a adequação do processo escolhido.
\end{abstract}

Palavras-chave: Gestão de segurança. Empresas da construção civil. Lógica Fuzzy. Indicadores de segurança. Modelo de mecanismos. 


\title{
Safety Evaluation in Construction Companies: a fuzzy logic application
}

\begin{abstract}
Construction industry (CI) stands as one of the most dangerous activities for workers. International Labour Organisation's (-ILO) estimates based on 2012 shows 2.3 million deaths per year due to lack of training. Estimates show that one in six fatal work accidents occur in the CI, which is responsible for at least 60,000 fatal accidents each year. This study uses fuzzy logic to establish a model of a mechanism that uses indicators to manage safety in construction companies. The model is based on national awards and management models, and introduces dimensions and a set of criteria that confirm the national award chosen to support the model is adequate.
\end{abstract}

KeYwords: Safety management. Construction companies. Fuzzy logic. Safety indicators. Mechanism model.

\section{Evaluación de seguridad en empresas de la construcción civil: una aplicación de la lógica difusa}

\section{Resumen}

La Industria de la Construcción (IC) es una de las actividades productivas de mayor peligro para los trabajadores, especialmente por el suceso de accidentes de trabajo fatales y no fatales. Estimativas de la OIT para el año 2012 muestran que son 2,3 millones de muertes por año resultantes de falta de capacitación. Se estima que también cada año ocurran por lo menos 60.000 accidentes fatales en la IC en todo el mundo, una muerte cada 10 minutos y uno cada seis accidentes fatales es en la IC. Este estudio tiene como objeto establecer un modelo de mecanismo gerencial de indicadores para la gestión de seguridad de empresas de construcción civil basado en programas nacionales de premios y modelos de gestión con aplicación de la lógica difusa. El modelo elaborado con base en esta lógica presenta dimensiones y criterios cuyos resultados apuntaron la adecuación del proceso elegido.

Palabras clave: Gestión de seguridad. Empresas de la construcción civil. Lógica difusa. Indicadores de seguridad. Modelo de mecanismos. 


\section{Introdução}

A evolução do homem não lhe trouxe apenas as benesses do progresso material, mas, também, novas preocupações como projetos, sistemas de gestão de diversos serviços, incluindo o combate aos acidentes de trabalho. Entretanto o que tem sido observado é a postura reativa, ou não efetiva, na gestão da segurança nas empresas da construção civil.

Com o mundo industrializando-se e as estruturas trabalhistas criadas na Europa, o Brasil aprovou o Decreto-Lei $n^{\circ} 5452$, em $1^{\circ}$ de Maio de 1943, a Consolidação das Leis do Trabalho (CLT), com o objetivo de regular as relações do trabalho urbano, a estrutura da justiça do trabalho e, proteger o trabalhador. Nesse caso, o empregado regido pela CLT passou a possuir seus registros de trabalho anotados em sua carteira profissional e, a ser chamado "celetista" (BRASIL, 1943).

A Portaria do Ministério do Trabalho No 3214/1978 aprovou as Normas Regulamentadoras, dentre elas a NR-18 - Programa de Condições de Trabalho na Indústria da Construção (PCMAT) - (Redação atual: Portaria no 4 de 4/7/1995 do MTE), que objetiva a implementação de medidas de controle e sistemas preventivos de segurança nos processos, nas condições de trabalho na indústria da construção, considerando os Serviços Especializados em Engenharia de Segurança e em Medicina do Trabalho (SESMT) e as atividades e serviços de demolição, reparo, pintura, limpeza e manutenção de edifícios em geral, incluindo urbanização e paisagismo (BRASIL, 1978).

O Quadro 1 apresenta a quantidade de acidentes de trabalho na construção civil, no período de 2006 a 2012, informando aqueles acidentes com Comunicação de Acidente de Trabalho (CAT) - (Típico, Trajeto e Doença do Trabalho), sem CAT e o Total de Acidentes ocorridos no Brasil e em percentual (BRASIL, 2014).

\section{QUADRO 1 \\ Quantidade de acidentes do trabalho por situação de registro e por motivo na construção civil - Seção F da CNAE Brasil 2006/2012}

\begin{tabular}{|c|c|c|c|c|c|c|c|}
\hline \multirow[b]{3}{*}{ ANO } & \multicolumn{5}{|c|}{ CONSTRUÇÃO CIVIL } & \multirow{3}{*}{$\begin{array}{l}\text { TOTAL DE } \\
\text { ACIDENTES } \\
\text { NO BRASIL } \\
\text { (B) }\end{array}$} & \multirow[b]{3}{*}{$(A / B) \%$} \\
\hline & \multicolumn{3}{|c|}{ Com CAT } & & \multirow[b]{2}{*}{$\begin{array}{c}\text { TOTAL } \\
\text { CONSTRUÇÃO } \\
\text { CIVIL (A) }\end{array}$} & & \\
\hline & TÍPICO & TRAJETO & $\begin{array}{c}\text { DOENÇA } \\
\text { DO } \\
\text { TRABALHO }\end{array}$ & Sem CAT & & & \\
\hline 2008 & 33.288 & 4.594 & 940 & 14.008 & 52.830 & 755.980 & $6,99 \%$ \\
\hline 2009 & 35.265 & 5.042 & 1.111 & 14.252 & 55.670 & 733.365 & $7,59 \%$ \\
\hline 2010 & 36.611 & 5.660 & 1.052 & 12.597 & 55.920 & 709.474 & $7,88 \%$ \\
\hline 2011 & 39.301 & 6.281 & 957 & 13.269 & 59.808 & 720.629 & $8,30 \%$ \\
\hline 2012 & 41.111 & 6.608 & 740 & 14.415 & 62.874 & 705.239 & $8,92 \%$ \\
\hline $\begin{array}{l}\text { Variação } \\
\text { 2012/2008 }\end{array}$ & $23.5 \%$ & $43.8 \%$ & $-21.3 \%$ & $2.9 \%$ & $19.0 \%$ & $-6.7 \%$ & $27.6 \%$ \\
\hline
\end{tabular}

Fonte: Informe da Previdência Social (2014). 
Complementando o Quadro 1, em 2013 foram registrados 40.465 acidentes típicos; 7.282 acidentes de trajeto e 762 casos de doença do trabalho, todos com CAT, atingindo a construção civil (CC) um número maior que 61.000 acidentes no Brasil (MTE/RAIS e MPS/AEPS apud NUNES, 2016)

Para Félix e Viana (2014 apud FREITAS, 2015), as longas jornadas de trabalho praticadas pelas empresas responsáveis pela construção em 2014 dos catorze estádios da Copa do Mundo no Brasil; o não cumprimento da Norma Reguladora - 18 (NR-18); a inexistência de Sistema de Gestão de Riscos e de Segurança e Saúde do Trabalho, eficazes e eficientes tiveram como consequência as catorze mortes por acidentes de trabalho (FUNDACENTRO, 2015).

Alguns autores afirmam que na construção civil as circunstâncias de acidentes ocorrem em consequência de procedimentos intensos e extensos de terceirizar as atividades laborais, considerando ser o setor de alta rotatividade, tanto no Rio de Janeiro/RJ como em São Paulo/SP (TAKAHASHI, SUN, HAMAMOTO, et al., 2012; MANGAS e MINAYO-GOMES, 2012 apud TODESCHINI, 2015).

A International Organization for Standardization (ISO) publicou, em 2010, a ISO 26000 Diretrizes Sobre Responsabilidade Social, a qual define que Responsabilidade Social aplica-se às instituições de qualquer porte, sejam públicas, privadas ou sem fins lucrativos (ALMEIDA, HENRIQUES, SILVA FILHO et al., 2015).

Segundo Martins, Cabral, Pessoa, et al. (2013), com o crescimento da gestão das atividades das organizações privadas em área pública, procura-se a concordância entre as instituições como um agente que segue para mais adiante com propósitos econômicos de lucratividade.

Por sua vez, o eSocial é uma atuação simultânea de diversas entidades federais: Secretaria da Receita Federal do Brasil (RFB), Caixa Econômica Federal, Instituto Nacional do Seguro Social (INSS) e os Ministérios do Trabalho e Previdência Social (MTPS) e Ministério do Planejamento. Ele contribui auxiliando essas entidades na uniformização dos assuntos relevantes a cada órgão sendo responsável pela gestão do programa por meio de sua Oficina de Projetos (BRASIL, 2015).

Verifica-se, então, que, para a empresa, a redução de custos, proteção da integridade dos trabalhadores, melhoria do ambiente de trabalho, eliminação de perdas patrimoniais, aumento de produtividade e competitividade, além da manutenção da boa imagem empresarial, constituem um bom negócio, que se traduz no investimento em ações de prevenção de acidentes de trabalho, por meio de uma gestão estratégica e de um plano eficaz (MOREIRA, 2015).

A atual crise política e econômica que o país atravessa leva a que a maioria das empresas da construção civil procure melhorar sua estrutura administrativa, com o fim de minimizar ou eliminar qualquer tipo de prejuízo financeiro ou à sua imagem empresarial, passando a investir em sistemas de gestão para garantir a integridade e o bem-estar de seus colaboradores, a valorização de seus empreendimentos e da sua marca perante a sociedade. Dessa forma, e na medida do possível, as empresas vão implantando sistemas: de Gestão da Qualidade; de Meio Ambiente; de Segurança e Saúde Ocupacional; de Responsabilidade Social e de Energia isolados ou em sistemas agrupados, que se tornam o Sistema de Gestão Integrado.

As auditorias não são executadas somente utilizando meios qualitativos e não necessariamente constatam a efetividade de um sistema em análise. Elas trazem as informações momentâneas da empresa, quando de sua execução. 
A aplicação da Lógica Fuzzy (ou Lógica Nebulosa) à proposta de avaliação da gestão de segurança em empresas da construção civil possibilita uma oportunidade de melhoria no reconhecimento de gestão eficiente e eficaz nas empresas. Desse modo, este artigo tem como objetivo apresentar uma proposta de modelo que utilize um sistema de indicadores de desempenho, para avaliar a gestão de segurança de empresas de construção civil. Ele é baseado em programas nacionais de premiação e modelos de gestão, sendo, ainda, consensado pela aplicação da Lógica Fuzzy.

$\mathrm{O}$ artigo é estruturado em cinco seções. A primeira apresenta um breve resumo e uma introdução ao tema da presente pesquisa. Na segunda seção, são descritos os aspectos da gestão de segurança das empresas da construção civil. Na terceira, identificam-se alguns modelos de avaliação adaptáveis à gestão de segurança das empresas da construção civil. A quarta sessão expõe a metodologia utilizada neste estudo, utilizando mecanismos de avaliação pela Lógica Fuzzy. A quinta e última sessão apresenta uma análise crítica conclusiva sobre o estudo realizado.

\section{Gestão de Segurança das Empresas da Construção Civil}

Na visão de Carneiro (2005), empresas da construção civil podem obter diversos benefícios através de: dispêndio com seguros atenuados; controle de gastos pela simplificação do uso de recursos naturais e redução de perdas; precaução contra possível contaminação ambiental; minoração de ocorrências de reparações e penalidades; valorização da imagem empresarial, além de outros, com a implementação da ABNT NBR ISO 14001 e consequente cumprimento da legislação pertinente. Afirma ainda que, em virtude de sua economia vulnerável, dispor processos de segurança em sistemas de gestão integrado é o obstáculo principal que as empresas identificam.

Duarte e Lordsleem Júnior (2009) postulam que em um Sistema de Gestão a aplicação de indicadores ordenadamente viabiliza a percepção de consequentes desvios sucedidos no ciclo do procedimento. A fim de lograr melhoria no processo, deve-se preestabelecer o ínterim entre as medições.

Nas instituições com sistema de gestão elaborado e integrado, torna-se mister que a execução de seus processos ocorra no seu âmbito a fim de tornarem-se eficazes já que a confirmação da ineficácia dos resultados das "auditorias" e "avaliações" não assegura o cumprimento de seu desempenho, assim como o cumprimento das diretrizes de sua política e requisitos legais (OHSAS, 2007).

No Brasil, a responsabilidade por grandes construções como usinas hidrelétricas, unidades de tratamento de água e esgoto, estádios, portos, aeroportos recai sobre as grandes construtoras, as quais são causadoras da elevada geração de acidentes, evitáveis em sua maioria. De acordo com Santana (2013), cerca de 7,1\% de todos os empregos formais no país, 2,6 milhões de postos de serviço - Câmara Brasileira da Indústria da Construção (CBIC) - e o Produto Interno Bruto (PIB) da Indústria da Construção (IC) correspondia a 5,1\%, em 2010, o que representa uma evolução dos 6,6\% anualmente em relação ao esperado.

De acordo com Segundo e Souza (2015), para auxiliar instituições a evoluir em suas práticas sustentáveis na gestão de seus sistemas e a fim de orientá-las, organizações internacionais aperfeiçoaram normas já padronizadas. Porém, pouco tempo depois, foi disponibilizada a nova norma ISO, a ISO 45001 (2016), colaborando com maior contribuição à saúde e à segurança do trabalho. 
Para Gordono, Carrijo, Fidencio et al. (2012), em reuniões governamentais, empresariais e acadêmicas, as discussões relativas a acidentes de trabalho é um assunto habitual, em virtude dos encargos e impactos financeiros que eles acarretam às empresas, à Previdência Social e aos trabalhadores brasileiros.

O Quadro 2 trata da insegurança no trabalho no Brasil em 2013, segundo a Pesquisa Nacional de Saúde do Instituto Brasileiro de Geografia e Estatística (IBGE) sobre o perfil dos acidentes no trabalho, indicando que: na divisão por sexo - trabalhadores do sexo masculino sofreram $73 \%$ dos acidentes e os do feminino, $23 \%$; por idade - aqueles que têm entre 18 e 29 anos estão no topo das estatísticas, com 33,9\%, contra 5,7\% daqueles com 60 anos ou mais, ocupando a parte mais baixa dessa classificação; por nível de instrução - os trabalhadores com nível médio completo e superior incompleto apresentam um índice de acidentes de 36,2\%, enquanto o daqueles com curso superior completo é de $8,2 \%$; por raça - o índice entre os trabalhadores pardos é de $45,6 \%$; os da raça branca, de $40,8 \%$; os da raça preta, de $12,6 \%$, e os de outra raça qualificada, de $1,0 \%$.

\section{QUADRO 2}

Perfil dos acidentados no trabalho, com 18 anos ou mais, IBGE 2013

\begin{tabular}{|c|c|c|}
\hline \multicolumn{3}{|c|}{ PERFIL DOS ACIDENTES NO TRABALHO, ENTRE PESSOAS COM 18 ANOS OU MAIS: } \\
\hline \multirow{2}{*}{ Por sexo } & Masculino & 3,963 milhões \\
\hline & Feminino & 1,455 milhão \\
\hline \multirow{4}{*}{ Por idade } & 18 a 29 anos & 1,676 milhão \\
\hline & 40 a 59 & 1,572 milhão \\
\hline & 30 a 49 anos & 1,417 milhão \\
\hline & 60 anos ou mais & $283 \mathrm{mil}$ \\
\hline \multirow{4}{*}{ Por nível de instrução } & Médio completo e superior incompleto & 1,791 milhão \\
\hline & Sem instrução e fundamental incompleto & 1,744 milhão \\
\hline & Fundamental completo e médio imcompleto & 1,006 milhão \\
\hline & Superior completo & $407 \mathrm{mil}$ \\
\hline \multirow{4}{*}{ Por raça } & Parda & 2,256 milhões \\
\hline & Branca & 2,018 milhões \\
\hline & Preta & $625 \mathrm{mil}$ \\
\hline & Outra & 49 mil \\
\hline
\end{tabular}

Fonte: O Globo (2015). 


\section{Modelos de Avaliação Adaptáveis à Gestão de Segurança das Empresas da Construção Civil}

Sintetizando os grandes prêmios da qualidade, nos Estados Unidos da América (EUA) - Malcolm Baldrige National Quality Award - MBNQA, na Europa European Quality Award - EQA, no Japão - Japan Quality Award - JQA e no Brasil - Prêmio Nacional da Qualidade - PNQ, dando maior destaque para o prêmio brasileiro. [...] O MBNQA, hoje chamado Baldridge Performance Excellence Program, estabelecido pelo Congresso Americano em 1987 e com os primeiros em 1988. [...] O processo é administrado pelo Baldrige National Quality Program, do National Institute of Standards and Technology (NIST), em conjunto com a American Society for Quality (ASQ) (SANTOS, CAMPOS e MIGUEL, 2014).

O European Quality Award, atual EFQM Excellence Award, é atribuído às organizações que demonstrem excelência na gestão de qualidade, como processo fundamental para a melhoria contínua. Criado em 1991, tem como promotor a Fundação Europeia para a Gestão de Qualidade (European Foundation for Quality Management) e a Organização Europeia para a Qualidade (European Organization for Quality Management) (CAUCHICK MIGUEL, 2004 apud SANTOS, CAMPOS e MIGUEL, 2014).

O Centro de Produtividade do Japão criou em 1995, o Japan Quality Award, para o Desenvolvimento Socioeconômico (JPC-SED). Modelado pela autoavaliação do Prêmio Malcolm Baldrige National Quality, nos EUA, e adequado às práticas de gestão japonesa, é concedido às empresas e entidades corporativas japonesas com excelência na qualidade em gestão global, (JAPAN QUALITY AWARD, 2013 apud SANTOS, CAMPOS e MIGUEL, 2014).

Para estabelecer um modelo de mecanismo gerencial de indicadores adaptável à gestão de segurança de empresas de construção civil, foram pesquisados os critérios adotados por três grandes prêmios nacionais:

- Prêmio Nacional da Qualidade (PNQ), promovido pela Fundação Nacional pela Qualidade (FNQ);

- Prêmio Nacional da Qualidade em Saneamento (PNQS), promovido pelo Comitê Nacional da Qualidade da Associação Brasileira de Engenharia Sanitária e Ambiental (ABES); e

- Prêmio Nacional da Qualidade de Vida (PNQV), promovido pela Associação Brasileira da Qualidade de Vida (ABQV).

Empresas declaradas bem-sucedidas foram avaliadas por um grupo norte-americano de peritos, na década de 1980 - o objetivo era identificar nelas particularidades comuns (OLIVEIRA e MARTINS, 2008). O reconhecimento da "performance" da instituição como parte integrante e relevante das técnicas de promoção da qualidade e da produtividade ocorreu com a criação de diversas premiações de excelência em qualidade (CAUCHICK MIGUEL, 2004 apud SANTOS, CAMPOS e MIGUEL, 2014). 
Conforme a FNQ (2013), os critérios do PNQ correspondem a uma representação prática dos Fundamentos de Excelência - os quais a FNQ objetiva disseminar - para fim de avaliação. Esses Fundamentos expressam conceitos reconhecidos internacionalmente e que se traduzem em práticas encontradas em organizações líderes de Classe Mundial. [...] Podem-se definir os fundamentos como os pilares, isto é, como a base teórica de uma gestão eficaz e eficiente (SANTOS, CAMPOS e MIGUEL, 2014).

O PNQS (2016) e o PNQV (2015) foram também escolhidos por utilizarem os mesmos Fundamentos de Excelência do PNQ (2013) e terem seus critérios de avaliação mais adequados às empresas de construção civil, conforme mostra o Quadro 3.

\section{QUADRO 3}

Critérios Comparativos entre Prêmios

\begin{tabular}{|c|c|c|}
\hline \multicolumn{3}{|c|}{ CRITÉRIOS COMPARATIVOS ENTRE OS TRÊS PRÊMIOS E O PRESENTE ESTUDO } \\
\hline Prêmios & Critérios & Estudo - Critério Adotado \\
\hline PNQ & Liderança & \multirow{3}{*}{ LIDERANÇA } \\
\hline PNQS & Liderança & \\
\hline PNQV & Liderança e Constância de Propósitos & \\
\hline PNQ & Estratégias e Planos & \multirow{3}{*}{-} \\
\hline PNQS & Estratégias e Planos & \\
\hline PNQV & Aprendizado Organizacional & \\
\hline PNQ & Clientes & \multirow{3}{*}{-} \\
\hline PNQS & Clientes & \\
\hline PNQV & Conhecimento do Cliente e do Mercado & \\
\hline PNQ & Sociedade & \multirow{3}{*}{ - } \\
\hline PNQS & Sociedade & \\
\hline PNQV & Responsabilidade Social & \\
\hline PNQ & Informação e Conhecimento & \multirow{3}{*}{ PROCESSOS } \\
\hline PNQS & Informação e Conhecimento & \\
\hline PNQV & Orientação por Processos e Informação & \\
\hline PNQ & Pessoas & \multirow{3}{*}{ PESSOAS } \\
\hline PNQS & Pessoas & \\
\hline PNQV & Valorização de Pessoas & \\
\hline PNQ & Processos & \multirow{3}{*}{ FORNECEDORES } \\
\hline PNQS & Processos & \\
\hline PNQV & Desenvolvimento de Parcerias & \\
\hline PNQ & Resultados & \multirow{3}{*}{ RESULTADOS } \\
\hline PNQS & Resultados & \\
\hline PNQV & Geração de Valor & \\
\hline PNQV & Visão do Futuro & \multirow{3}{*}{-} \\
\hline PNQV & Pensamento Sistêmico & \\
\hline PNQV & Cultura da Inovação & \\
\hline
\end{tabular}

Fonte: Elaborado pelos autores. 


\section{Metodologia}

\section{Mecanismos de avaliação pela lógica Fuzzy}

O Sistema Lógico Fuzzy estrutura-se em três passos, explicitados na Figura 1, adaptada de Cox (1995). No primeiro passo, tem-se a "fuzificação" (2), na qual ocorre a transformação dos dados iniciais (1) em variáveis linguísticas (3), fase em que todas as informações relativas à imprecisão ou incerteza associada a estas variáveis devem ser consideradas. No segundo passo, adequados os valores iniciais em variáveis linguísticas (3), a "inferência” Fuzzy é a fase seguinte (4), cujo fim é comparar entre si as prováveis variáveis por meio de normas preestabelecidas, com os objetivos do algoritmo atingidos. Do sistema lógico Fuzzy, a "defuzificação" é o terceiro e último passo (6) e compreende, segundo Altrock (1996), o resultado linguístico interpretado (5) da metodologia de "inferência" Fuzzy em elementos finais (7), em valor numérico (JANÉ, 2004). Porém, Cox (1995 apud JANÉ, 2004) dá à “defuzificação" outra leitura (6), na qual interpreta o método de transformação de um valor Fuzzy em um número real.

FIGURA 1

Sistema Lógico Fuzzy

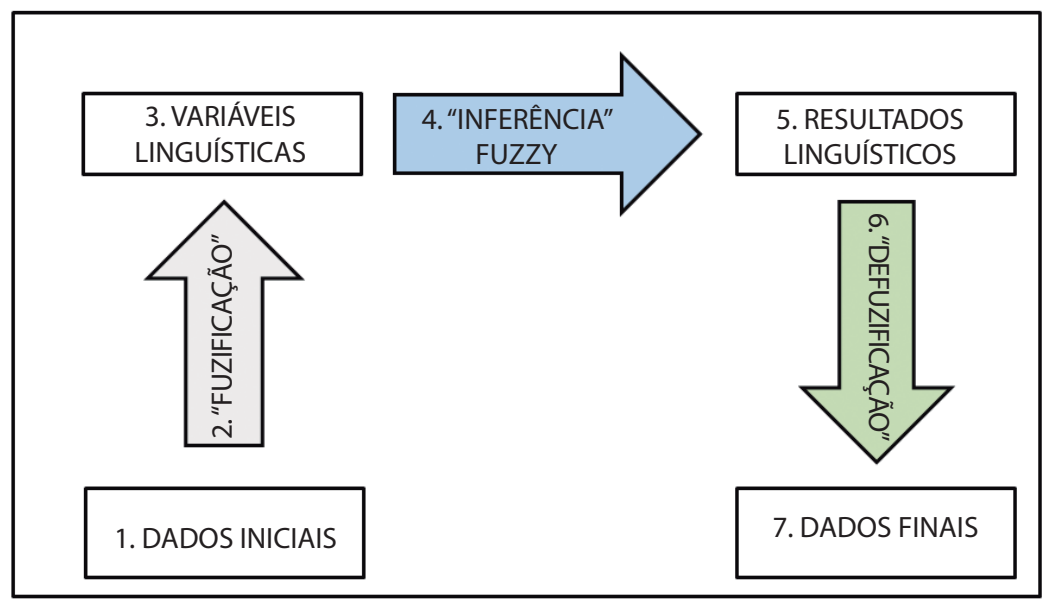

Fonte: $\operatorname{Cox}(1995)$.

O Quadro 4 apresenta o Processo Metodológico da pesquisa, que foi desenvolvida em três fases: 1. Indicadores de Segurança; 2. Sistema de "Inferência" Fuzzy; 3. Experimento do Modelo Proposto. Cada fase é composta por três etapas: 1.1 Modelo de Gavião e Lima (2014); 1.2 Entrevistas com Especialistas; e 1.3 Adaptação das Métricas aos Indicadores; 2.1 Desenvolvimento dos Conjuntos Fuzzy; 2.2 Desenvolvimento das Regras de "Inferência"; e 2.3 Simulação no software Matlab R2013a; 3.1 Compilação do Algoritmo de Agregação dos Indicadores; 3.2 Simulação dos Resultados em 3D; e 3.3 Conclusão. 


\section{QUADRO 4}

\section{Processo Metodológico}

\begin{tabular}{|c|c|}
\hline FASE & ETAPA \\
\hline \multirow[t]{3}{*}{ 1. Indicadores de Segurança } & 1.1 Modelo de Gavião e Lima (2014), adaptado \\
\hline & 1.2 Entrevistas com Especialistas \\
\hline & 1.3 Adaptação das Métricas aos Indicadores \\
\hline \multirow[t]{3}{*}{ 2. Sistema de "Inferência" Fuzzy } & 2.1 Desenvolvimento dos Conjuntos Fuzzy \\
\hline & 2.2 Desenvolvimento das Regras de "Inferência" \\
\hline & 2.3 Simulação no software MatLab R2013a \\
\hline \multirow[t]{3}{*}{ 3. Experimento do Modelo Proposto } & 3.1 Compilação do Algoritmo de Agregação dos Indicadores \\
\hline & 3.2 Simulação dos Resultados em 3D \\
\hline & 3.3 Conclusão \\
\hline
\end{tabular}

Fonte: Elaborado pelos autores.

A etapa 1.1, Modelo adaptado de Gavião e Lima (2014), adaptado, consiste na identificação dos indicadores de segurança para a indústria da construção civil, os quais foram pesquisados na literatura baseada na lógica Fuzzy. Esta etapa teve como objetivo buscar o referencial teórico dos indicadores utilizados em três grandes prêmios nacionais para empresas (Qualidade, Qualidade em Saneamento e Qualidade de Vida).

A Figura 2 apresenta o Sistema de "Inferência" Fuzzy, fase 2, que tem a sua apresentação antecipada para facilitar o entendimento do texto, uma vez que permeia as etapas 1.1, 1.2 e 1.3 da fase 1, com uma visão única da proposição do modelo no qual se obtém o Índice de Segurança. Esse Sistema apresenta cinco dimensões: SIF 1 - Liderança; SIF 2 - Fornecedores; SIF 3 - Pessoas; SIF 4 - Processos; e, SIF 5 - Resultados (após a realização da "Inferência" Fuzzy). O SIF 6 passa a apontar o Índice de Segurança.

FIGURA 2

Sistema de "Inferência” Fuzzy (Índice de Segurança)

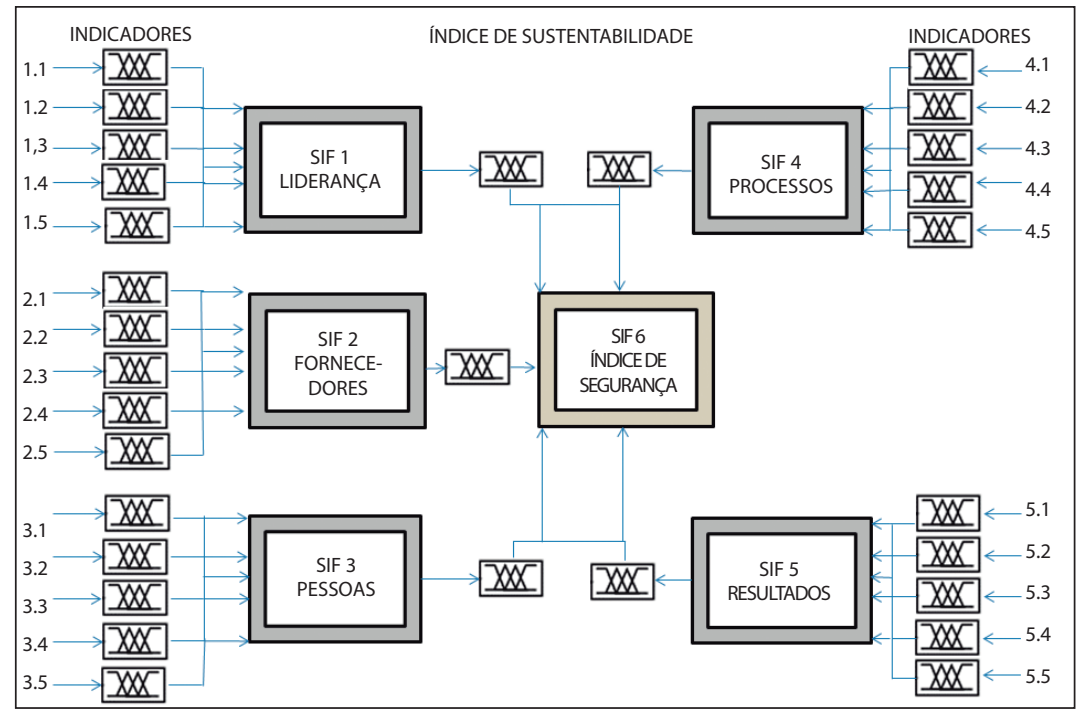

Fonte: Adaptada de Gavião e Lima (2014). 
A etapa 1.2 consistiu da entrevista de oito especialistas com experiência no ramo das engenharias: civil; de segurança; de produção; mecânica; elétrica; e meio ambiente; bem como o de consultores da lógica Fuzzy, todos envolvidos com o aperfeiçoamento dos indicadores obtidos no referencial teórico, o que está em conformidade com as diretrizes de knowledge engineering relatadas por Klir e Yuan (1995) e Cox (1999 apud GAVIÃO e LIMA, 2014). Estão dispostas nos Quadros de 6 a 10 as informações que resultaram dessa entrevista: Dimensão, Descrição, Itens de Avaliação e Indicador.

Para a etapa 1.3, verificou-se que a pontuação atribuída a cada Dimensão (ou Critério) de Avaliação atingiu um máximo de 200 pontos, pois se considerou que todas as Dimensões (Liderança, Fornecedores, Pessoas, Processos e Resultados) teriam o mesmo peso. A Figura 3 apresenta os Critérios, Categorias e Pontuações, neles constam as faixas de pontuação de cada Critério de Avaliação, além dos níveis de pontuação para enquadrar as empresas nas categorias de resultados que elas possam obter em sua avaliação global, assim como a pontuação é feita da seguinte forma: Menção Honrosa - 0 a 200; Bronze - 201 a 400; Prata - 401 a 600; Ouro - 601 a 800; Excelência em Segurança - 801 a 1000.

\section{QUADRO 5}

\section{Critérios, Categorias e Pontuações de Avaliações}

\begin{tabular}{|lc|}
\hline CRITÉRIOS & PONTUAÇÃO \\
\hline 1 - Liderança & 200 \\
\hline 2 - Fornecedores & 200 \\
\hline 3 - Pessoas & 200 \\
\hline 4 - Processos & 200 \\
\hline 5 - Resultados & 200 \\
\hline \multicolumn{1}{|c|}{ CATEGORIA } & PONTUAÇÃO \\
\hline Menção Honrosa & 0 a 200 \\
\hline Bronze & 201 a 400 \\
\hline Prata & 401 a 600 \\
\hline Ouro & 601 a 800 \\
\hline Excelência em Segurança & 801 a 1000 \\
\hline
\end{tabular}

Fonte: Elaborado pelos autores.

Concluindo essa primeira fase, foram determinadas as métricas dos indicadores, de acordo com os valores das variáveis obtidas com os especialistas, conforme indicam os Quadros de 6 a 10. Neles a pontuação atribuída foi de 0 a 40 em todos os subitens. Já a métrica, em todos os subitens, foi dividida em cinco partes iguais: de 0 a 8 - "Muito Baixo" (MB); de 9 a 16 - "Baixo" (B); de 17 a 24 - "Médio" (M); de 25 a 32 - "Alto" (A); de 33 a 40 - "Muito Alto" (MA) - conforme apresentados nas colunas de Pontuação e Métrica dos quadros supracitados. 


\section{QUADRO 6 \\ Dimensão: Liderança (20\%)}

SEGURANÇA NA CONSTRUÇÃO CIVIL - 1.000 pontos

\begin{tabular}{|c|c|c|c|}
\hline DIMENSÃO & \multicolumn{2}{|l|}{ DESCRIÇÃO } & PONTUAÇÃO \\
\hline LIDERANÇA & \multicolumn{2}{|c|}{$\begin{array}{l}\text { Este Critério aborda processos gerenciais } \\
\text { relativos à cultura organizacional e } \\
\text { desenvolvimento da gestão, governança, } \\
\text { exercício da liderança e análise do } \\
\text { desempenho da organização em relação } \\
\text { à função segurança. }\end{array}$} & 0 a 200 \\
\hline ITENS DE AVALIAÇÃO & INDICADOR & PONTUAÇÃO & MÉTRICA \\
\hline \multirow{5}{*}{$\begin{array}{l}\text { 1.1 A função Segurança está } \\
\text { contemplada nas diretrizes } \\
\text { superiores da empresa (Os } \\
\text { Valores organizacionais } \\
\text { consideram a segurança). }\end{array}$} & \multirow{5}{*}{$\begin{array}{l}\text { Evidências da menção } \\
\text { segurança nos padrões da } \\
\text { organização. }\end{array}$} & \multirow{5}{*}{0 a 40} & 0 a 8 Muito Baixo \\
\hline & & & 9 a 16 Baixo \\
\hline & & & 17 a 24 Médio \\
\hline & & & 25 a 32 Alto \\
\hline & & & 33 a 40 Muito Alto \\
\hline \multirow{5}{*}{$\begin{array}{l}\text { 1.2 A função Segurança } \\
\text { está contida nas normas } \\
\text { gerenciais. }\end{array}$} & \multirow{5}{*}{$\begin{array}{l}\text { Evidências objetivas da } \\
\text { função Segurança nas } \\
\text { normas gerenciais. }\end{array}$} & \multirow{5}{*}{0 a 40} & 0 a 8 Muito Baixo \\
\hline & & & 9 a 16 Baixo \\
\hline & & & 17 a 24 Médio \\
\hline & & & 25 a 32 Alto \\
\hline & & & 33 a 40 Muito Alto \\
\hline \multirow{5}{*}{$\begin{array}{l}1.3 \text { A alta administração participa } \\
\text { de eventos de segurança. }\end{array}$} & \multirow{5}{*}{$\begin{array}{l}\text { Evidências de participação } \\
\text { da alta administração } \\
\text { em eventos internos e } \\
\text { externos. }\end{array}$} & \multirow{5}{*}{0 a 40} & 0 a 8 Muito Baixo \\
\hline & & & 9 a 16 Baixo \\
\hline & & & 17 a 24 Médio \\
\hline & & & 25 a 32 Alto \\
\hline & & & 33 a 40 Muito Alto \\
\hline \multirow{5}{*}{$\begin{array}{l}\text { 1.4 A organização interage } \\
\text { com as partes interessadas } \\
\text { sobre os aspectos da Gestão da } \\
\text { Segurança. }\end{array}$} & \multirow{5}{*}{$\begin{array}{l}\text { Evidências de registros } \\
\text { com partes interessadas. }\end{array}$} & \multirow{5}{*}{0 a 40} & 0 a 8 Muito Baixo \\
\hline & & & 9 a 16 Baixo \\
\hline & & & 17 a 24 Médio \\
\hline & & & 25 a 32 Alto \\
\hline & & & 33 a 40 Muito Alto \\
\hline \multirow{5}{*}{$\begin{array}{l}1.5 \text { É promovida a melhoria nos } \\
\text { processos gerenciais da função } \\
\text { Segurança. }\end{array}$} & \multirow{5}{*}{$\begin{array}{l}\text { Evidências do } \\
\text { cumprimento das normas } \\
\text { gerenciais relativos aos } \\
\text { processos gerenciais mais } \\
\text { importantes. }\end{array}$} & \multirow{5}{*}{0 a 40} & 0 a 8 Muito Baixo \\
\hline & & & 9 a 16 Baixo \\
\hline & & & 17 a 24 Médio \\
\hline & & & 25 a 32 Alto \\
\hline & & & 33 a 40 Muito Alto \\
\hline
\end{tabular}

Fonte: Elaborado pelos autores. 


\section{QUADRO 7}

Dimensão: Fornecedores (20\%)

\begin{tabular}{|c|c|c|c|}
\hline CRITÉRIO & \multicolumn{2}{|c|}{ DESCRIÇÃO } & PONTUAÇÃO \\
\hline FORNECEDORES & \multicolumn{2}{|c|}{$\begin{array}{l}\text { Este Critério aborda processos gerenciais } \\
\text { relativos à função segurança na seleção } \\
\text { e relacionamento com os fornecedores } \\
\text { da organização. }\end{array}$} & 0 a 200 \\
\hline ITENS DE AVALIAÇÃO & INDICADOR & PONTUAÇÃO & MÉTRICA \\
\hline \multirow{5}{*}{$\begin{array}{l}2.1 \text { O contrato do Fornecedor } \\
\text { contempla a função segurança. }\end{array}$} & \multirow{5}{*}{$\begin{array}{l}\text { Evidência da função } \\
\text { segurança e normas } \\
\text { de contrato do } \\
\text { fornecedor, de acordo } \\
\text { com a NBR ISO } \\
9001 / 2015 \text {. }\end{array}$} & \multirow{5}{*}{0 a 40} & 0 a 8 Muito Baixo \\
\hline & & & 9 a 16 Baixo \\
\hline & & & 17 a 24 Médio \\
\hline & & & 25 a 32 Alto \\
\hline & & & 33 a 40 Muito Alto \\
\hline \multirow{5}{*}{$\begin{array}{l}2.2 \text { No contrato do fornecedor } \\
\text { está previsto treinamento } \\
\text { introdutório de segurança. }\end{array}$} & \multirow{5}{*}{$\begin{array}{l}\text { Evidência de normas } \\
\text { de treinamento } \\
\text { introdutório de } \\
\text { segurança, de acordo } \\
\text { com a NBR ISO } \\
9001 / 2015 \text {. }\end{array}$} & \multirow{5}{*}{0 a 40} & 0 a 8 Muito Baixo \\
\hline & & & 9 a 16 Baixo \\
\hline & & & 17 a 24 Médio \\
\hline & & & 25 a 32 Alto \\
\hline & & & 33 a 40 Muito Alto \\
\hline \multirow{5}{*}{$\begin{array}{l}2.3 \text { O fornecedor dispõe de } \\
\text { supervisor para as normas de } \\
\text { segurança. }\end{array}$} & \multirow{5}{*}{$\begin{array}{l}\text { Evidências de } \\
\text { supervisão no } \\
\text { cumprimento das } \\
\text { normas de segurança, } \\
\text { de acordo com a NBR } \\
\text { ISO 9001/2015. }\end{array}$} & \multirow{5}{*}{0 a 40} & 0 a 8 Muito Baixo \\
\hline & & & 9 a 16 Baixo \\
\hline & & & 17 a 24 Médio \\
\hline & & & 25 a 32 Alto \\
\hline & & & 33 a 40 Muito Alto \\
\hline \multirow{5}{*}{$\begin{array}{l}\text { 2.4 A organização audita seus } \\
\text { fornecedores. }\end{array}$} & \multirow{5}{*}{$\begin{array}{l}\text { Evidência da } \\
\text { realização de auditoria } \\
\text { em seus fornecedores, } \\
\text { de acordo com a NBR } \\
\text { ISO } 9001 / 2015 \text { em } \\
\text { relação à Segurança. }\end{array}$} & \multirow{5}{*}{0 a 40} & 0 a 8 Muito Baixo \\
\hline & & & 9 a 16 Baixo \\
\hline & & & 17 a 24 Médio \\
\hline & & & 25 a 32 Alto \\
\hline & & & 33 a 40 Muito Alto \\
\hline \multirow{5}{*}{$\begin{array}{l}2.5 \text { A organização promove } \\
\text { a melhoria nos processos } \\
\text { gerenciais. }\end{array}$} & \multirow{5}{*}{$\begin{array}{l}\text { Evidência de realização } \\
\text { de melhorias nos } \\
\text { processos gerenciais } \\
\text { mais importantes, de } \\
\text { acordo com a NBR ISO } \\
9001 / 2015 \text { da função } \\
\text { Segurança. }\end{array}$} & \multirow{5}{*}{0 a 40} & 0 a 8 Muito Baixo \\
\hline & & & 9 a 16 Baixo \\
\hline & & & 17 a 24 Médio \\
\hline & & & 25 a 32 Alto \\
\hline & & & 33 a 40 Muito Alto \\
\hline
\end{tabular}

Fonte: Elaborado pelos autores. 


\section{QUADRO 8}

Dimensão: Pessoas (20\%)

\begin{tabular}{|c|c|c|c|}
\hline CRITÉRIO & \multicolumn{2}{|c|}{ DESCRIÇÃO } & PONTUAÇÃO \\
\hline PESSOAS & \multicolumn{2}{|c|}{$\begin{array}{l}\text { Este Critério aborda os aspectos da } \\
\text { Segurança nos processos gerenciais } \\
\text { relativos aos sistemas de trabalho, à } \\
\text { capacitação e desenvolvimento e à } \\
\text { qualidade de vida. }\end{array}$} & 0 a 200 \\
\hline ITENS DE AVALIAÇÃO & INDICADOR & PONTUAÇÃO & MÉTRICA \\
\hline \multirow{5}{*}{$\begin{array}{l}3.1 \text { A organização identifica as } \\
\text { atividades críticas para o seu } \\
\text { pessoal em relação aos aspectos } \\
\text { de segurança. }\end{array}$} & \multirow{5}{*}{$\begin{array}{l}\text { Evidências da } \\
\text { identificação do } \\
\text { perfil profissiográfico } \\
\text { da execução de } \\
\text { atividades. }\end{array}$} & \multirow{5}{*}{0 a 40} & 0 a 8 Muito Baixo \\
\hline & & & 9 a 16 Baixo \\
\hline & & & 17 a 24 Médio \\
\hline & & & 25 a 32 Alto \\
\hline & & & 33 a 40 Muito Alto \\
\hline \multirow{5}{*}{$\begin{array}{l}3.2 \text { A organização executa } \\
\text { treinamento em atividades críticas } \\
\text { em relação à Segurança. }\end{array}$} & \multirow{5}{*}{$\begin{array}{l}\text { Evidências da } \\
\text { identificação } \\
\text { da execução de } \\
\text { treinamento em } \\
\text { atividades críticas. }\end{array}$} & \multirow{5}{*}{0 a 40} & 0 a 8 Muito Baixo \\
\hline & & & 9 a 16 Baixo \\
\hline & & & 17 a 24 Médio \\
\hline & & & 25 a 32 Alto \\
\hline & & & 33 a 40 Muito Alto \\
\hline \multirow{5}{*}{$\begin{array}{l}3.3 \text { A organização promove } \\
\text { atualização periódica da } \\
\text { capacitação de seus profissionais } \\
\text { frente aos aspectos da segurança. }\end{array}$} & \multirow{5}{*}{$\begin{array}{l}\text { Evidências da } \\
\text { identificação } \\
\text { de registros da } \\
\text { atualização periódica } \\
\text { da capacitação de } \\
\text { seus profissionais. }\end{array}$} & \multirow{5}{*}{0 a 40} & 0 a 8 Muito Baixo \\
\hline & & & 9 a 16 Baixo \\
\hline & & & 17 a 24 Médio \\
\hline & & & 25 a 32 Alto \\
\hline & & & 33 a 40 Muito Alto \\
\hline \multirow{5}{*}{$\begin{array}{l}\text { 3.4 A organização promove } \\
\text { melhorias nos processos de } \\
\text { treinamentos }\end{array}$} & \multirow{5}{*}{$\begin{array}{l}\text { Evidência de } \\
\text { execução de } \\
\text { programas de } \\
\text { melhorias nos } \\
\text { processos de } \\
\text { treinamentos. }\end{array}$} & \multirow{5}{*}{0 a 40} & 0 a 8 Muito Baixo \\
\hline & & & 9 a 16 Baixo \\
\hline & & & 17 a 24 Médio \\
\hline & & & 25 a 32 Alto \\
\hline & & & 33 a 40 Muito Alto \\
\hline \multirow{5}{*}{$\begin{array}{l}3.5 \text { A organização promove } \\
\text { melhorias no programa de } \\
\text { qualidade de vida no trabalho. }\end{array}$} & \multirow{5}{*}{$\begin{array}{l}\text { Evidência de } \\
\text { execução de } \\
\text { melhorias no } \\
\text { programa de } \\
\text { qualidade de vida no } \\
\text { Trabalho. }\end{array}$} & \multirow{5}{*}{0 a 40} & 0 a 8 Muito Baixo \\
\hline & & & 9 a 16 Baixo \\
\hline & & & 17 a 24 Médio \\
\hline & & & 25 a 32 Alto \\
\hline & & & 33 a 40 Muito Alto \\
\hline
\end{tabular}

Fonte: Elaborado pelos autores. 


\section{QUADRO 9}

\section{Dimensão: Processos (20\%)}

\begin{tabular}{|c|c|c|c|}
\hline CRITÉRIO & \multicolumn{2}{|l|}{ DESCRIÇÃO } & PONTUAÇÃO \\
\hline PROCESSOS & \multicolumn{2}{|c|}{$\begin{array}{l}\text { Este Critério aborda os processos } \\
\text { principais de seu negócio relativos à } \\
\text { cadeia de valor e processos econômico- } \\
\text { financeiros em relação aos aspectos da } \\
\text { Segurança. }\end{array}$} & 0 a 200 \\
\hline ITENS DE AVALIAÇÃO & INDICADOR & PONTUAÇÃO & MÉTRICA \\
\hline \multirow{5}{*}{$\begin{array}{l}\text { 4.1 A organização estabelece } \\
\text { planejamento das atividades } \\
\text { críticas de trabalho, } \\
\text { considerando os aspectos de } \\
\text { segurança. }\end{array}$} & \multirow{5}{*}{$\begin{array}{l}\text { Evidência de registro } \\
\text { de planejamento das } \\
\text { atividades de críticas de } \\
\text { trabalho, considerando } \\
\text { os aspectos de } \\
\text { segurança. }\end{array}$} & \multirow{5}{*}{0 a 40} & 0 a 8 Muito Baixo \\
\hline & & & 9 a 16 Baixo \\
\hline & & & 17 a 24 Médio \\
\hline & & & 25 a 32 Alto \\
\hline & & & 33 a 40 Muito Alto \\
\hline \multirow{5}{*}{$\begin{array}{l}4.2 \text { A organização utiliza uma } \\
\text { metodologia para desenvolver } \\
\text { novos produtos contemplando } \\
\text { a função Segurança. }\end{array}$} & \multirow{5}{*}{$\begin{array}{l}\text { Evidência de registro } \\
\text { de utilização de } \\
\text { metodologias de } \\
\text { projeto para o } \\
\text { desenvolvimento de } \\
\text { novos produtos. }\end{array}$} & \multirow{5}{*}{0 a 40} & 0 a 8 Muito Baixo \\
\hline & & & 9 a 16 Baixo \\
\hline & & & 17 a 24 Médio \\
\hline & & & 25 a 32 Alto \\
\hline & & & 33 a 40 Muito Alto \\
\hline \multirow{5}{*}{$\begin{array}{l}4.3 \text { A organização gerencia os } \\
\text { riscos dos processos principais } \\
\text { de seu negócio em relação à } \\
\text { Segurança do Trabalho. }\end{array}$} & \multirow{5}{*}{$\begin{array}{l}\text { Evidência do } \\
\text { gerenciamento de riscos } \\
\text { dos processos principais } \\
\text { de seu negócio. }\end{array}$} & \multirow{5}{*}{0 a 40} & 0 a 8 Muito Baixo \\
\hline & & & 9 a 16 Baixo \\
\hline & & & 17 a 24 Médio \\
\hline & & & 25 a 32 Alto \\
\hline & & & 33 a 40 Muito Alto \\
\hline \multirow{5}{*}{$\begin{array}{l}\text { 4.4 A organização gerencia os } \\
\text { riscos dos processos econômico- } \\
\text { financeiros que possam ser } \\
\text { diretamente impactados pelos } \\
\text { aspectos da Segurança. }\end{array}$} & \multirow{5}{*}{$\begin{array}{l}\text { Evidência do } \\
\text { gerenciamento de } \\
\text { riscos dos processos } \\
\text { econômico-financeiros. }\end{array}$} & \multirow{5}{*}{0 a 40} & 0 a 8 Muito Baixo \\
\hline & & & 9 a 16 Baixo \\
\hline & & & 17 a 24 Médio \\
\hline & & & 25 a 32 Alto \\
\hline & & & 33 a 40 Muito Alto \\
\hline \multirow{5}{*}{$\begin{array}{l}4.5 \text { A organização audita riscos } \\
\text { dos processos principais de } \\
\text { seu negócio e dos processos } \\
\text { econômico-financeiros que } \\
\text { possam ser diretamente } \\
\text { impactados pelos aspectos da } \\
\text { Segurança. }\end{array}$} & \multirow{5}{*}{$\begin{array}{l}\text { Evidência de sistema } \\
\text { de gerenciamento de } \\
\text { auditoria. }\end{array}$} & \multirow{5}{*}{0 a 40} & 0 a 8 Muito Baixo \\
\hline & & & 9 a 16 Baixo \\
\hline & & & 17 a 24 Médio \\
\hline & & & 25 a 32 Alto \\
\hline & & & 33 a 40 Muito Alto \\
\hline
\end{tabular}

Fonte: Elaborado pelos autores. 


\section{QUADRO 10}

\section{Dimensão: Resultados (20\%)}

\begin{tabular}{|c|c|c|c|}
\hline CRITÉRIO & \multicolumn{2}{|l|}{ DESCRIÇÃO } & PONTUAÇÃO \\
\hline RESULTADOS & \multicolumn{2}{|c|}{$\begin{array}{l}\text { Este Critério aborda a apresentação de resultados } \\
\text { estratégicos e operacionais relevantes para } \\
\text { a organização, na forma de indicadores que } \\
\text { permitam avaliar, no conjunto, a melhoria } \\
\text { dos resultados, o nível de competitividade e o } \\
\text { cumprimento de compromissos com requisitos } \\
\text { de partes interessadas nas perspectivas } \\
\text { econômico-financeira, socioambiental e relativas } \\
\text { a clientes e mercados, a pessoas e aos processos } \\
\text { da cadeia de valor. }\end{array}$} & 0 a 200 \\
\hline ITENS DE AVALIAÇÃO & INDICADOR & PONTUAÇÃO & MÉTRICA \\
\hline \multirow{5}{*}{$\begin{array}{l}5.1 \text { As competências } \\
\text { necessárias para o exercício } \\
\text { pleno das funções pelas } \\
\text { pessoas, incluindo líderes, são } \\
\text { identificadas. }\end{array}$} & \multirow{5}{*}{\multicolumn{2}{|c|}{$\begin{array}{l}\text { Apresentar as principais } \\
\text { competências identificadas } \\
\text { para as pessoas em gera } \\
\text { e especificamente para os } \\
\text { líderes. }\end{array}$}} & 0 a 8 Muito Baixo \\
\hline & & & 9 a 16 Baixo \\
\hline & & & 17 a 24 Médio \\
\hline & & & 25 a 32 Alto \\
\hline & & & 33 a 40 Muito Alto \\
\hline \multirow{5}{*}{$\begin{array}{l}5.2 \text { A organização promove } \\
\text { programas de prevenção à } \\
\text { acidentes de trabalho. }\end{array}$} & \multirow{5}{*}{$\begin{array}{l}\text { Evidência de redução dos } \\
\text { índices de acidentes. }\end{array}$} & \multirow{5}{*}{0 a 40} & 0 a 8 Muito Baixo \\
\hline & & & 9 a 16 Baixo \\
\hline & & & 17 a 24 Médio \\
\hline & & & 25 a 32 Alto \\
\hline & & & 33 a 40 Muito Alto \\
\hline \multirow{5}{*}{$\begin{array}{l}5.3 \text { A organização apresenta } \\
\text { os resultados dos principais } \\
\text { indicadores relativos a pessoas, } \\
\text { incluindo os referentes } \\
\text { ao sistema de trabalho, } \\
\text { capacitação e desenvolvimento } \\
\text { e qualidade de vida, bem } \\
\text { como os referentes à liderança, } \\
\text { comunicação e cultura. }\end{array}$} & \multirow{5}{*}{$\begin{array}{l}\text { Identificação dos registros } \\
\text { com os resultados dos } \\
\text { indicadores relativos a } \\
\text { pessoas, ao sistema de } \\
\text { trabalho, à capacitação } \\
\text { e desenvolvimento e } \\
\text { qualidade de vida, liderança, } \\
\text { comunicação e cultura. }\end{array}$} & \multirow{5}{*}{0 a 40} & 0 a 8 Muito Baixo \\
\hline & & & 9 a 16 Baixo \\
\hline & & & 17 a 24 Médio \\
\hline & & & 25 a 32 Alto \\
\hline & & & 33 a 40 Muito Alto \\
\hline \multirow{5}{*}{$\begin{array}{l}5.4 \text { A organização apresenta } \\
\text { os resultados dos principais } \\
\text { indicadores relativos a } \\
\text { produtos, aos processos } \\
\text { principais do seu negócio, } \\
\text { dos seus fornecedores e } \\
\text { econômico-financeiros. }\end{array}$} & \multirow{5}{*}{$\begin{array}{l}\text { Identificação dos registros } \\
\text { dos principais indicadores } \\
\text { relativos aos produtos, } \\
\text { aos processos principais } \\
\text { do seu negócio, dos seus } \\
\text { fornecedores e econômico- } \\
\text { financeiros. }\end{array}$} & \multirow{5}{*}{0 a 40} & 0 a 8 Muito Baixo \\
\hline & & & 9 a 16 Baixo \\
\hline & & & 17 a 24 Médio \\
\hline & & & 25 a 32 Alto \\
\hline & & & 33 a 40 Muito Alto \\
\hline \multirow{5}{*}{$\begin{array}{l}5.5 \text { Os resultados sociais e } \\
\text { ambientais apresentados } \\
\text { são reconhecidos como } \\
\text { adequados à organização. }\end{array}$} & \multirow{5}{*}{$\begin{array}{l}\text { Evidência de registros dos } \\
\text { principais resultados sociais } \\
\text { e ambientais. }\end{array}$} & \multirow{5}{*}{0 a 40} & 0 a 8 Muito Baixo \\
\hline & & & 9 a 16 Baixo \\
\hline & & & 17 a 24 Médio \\
\hline & & & 25 a 32 Alto \\
\hline & & & 33 a 40 Muito Alto \\
\hline
\end{tabular}


$\mathrm{Na}$ segunda fase foi desenvolvido o Sistema de "Inferência" Fuzzy, com a finalidade de agregar os dados para a produção de indicadores nos critérios Liderança, Fornecedores, Pessoas, Processos e Resultados, além do Índice de Segurança.

A Figura 3 apresenta o Modelo Fuzzy com as entradas (inputs). Foi atribuído primeiro (1) um conjunto de pontuações para cada critério avaliado. Em seguida (2), foram agregadas as pontuações por meio do SIF proposto. Por fim (3), o modelo foi testado em empresa hipotética.

FIGURA 3

Representação gráfica do modelo proposto

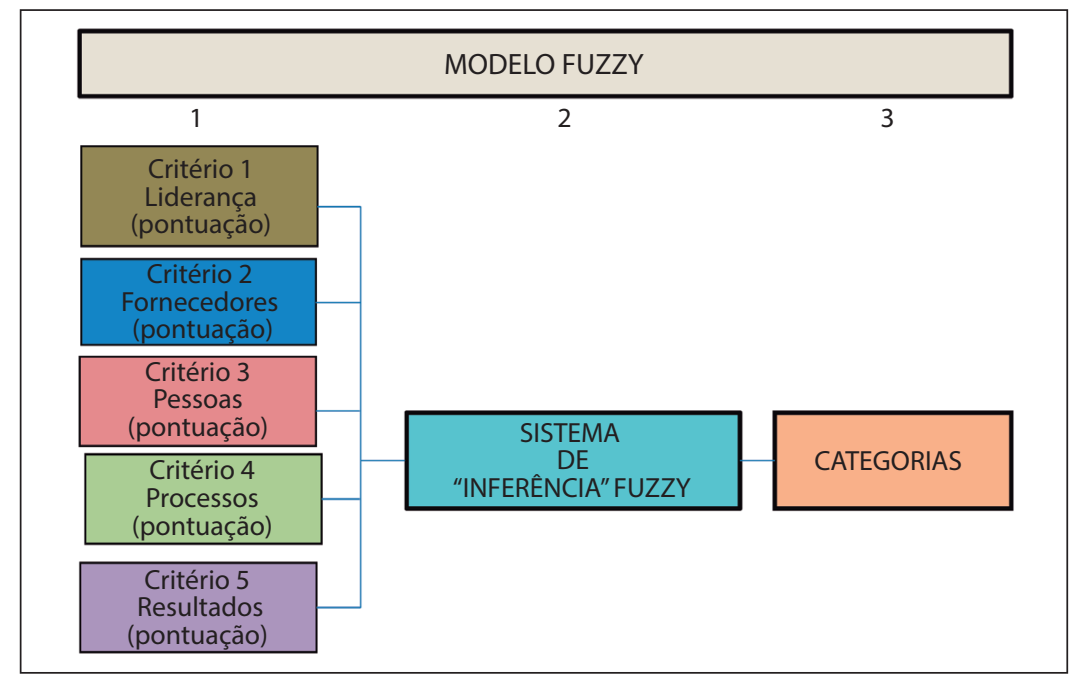

Fonte: Elaborada pelos autores.

Para atingir os objetivos dessa fase, ela foi desdobrada em três atos sendo que o primeiro transformou os dados obtidos nas entrevistas nos conjuntos Fuzzy: "Muito Baixo", "Baixo", "Médio", "Alto", "Muito Alto", para cada indicador, com funções de pertinência triangulares e trapezoidais, caracterizadas pelo terno a, b e c. Onde a e c determinam o intervalo no qual a função de pertinência assume valores diferentes de zero, e b é o ponto onde a função de pertinência é máxima, conforme mostra a Figura 4, Sistema de Inferência Fuzzy, segundo o Tutorial Fuzzy MatLab.

FIGURA 4

\section{Sistema de Inferência Fuzzy}

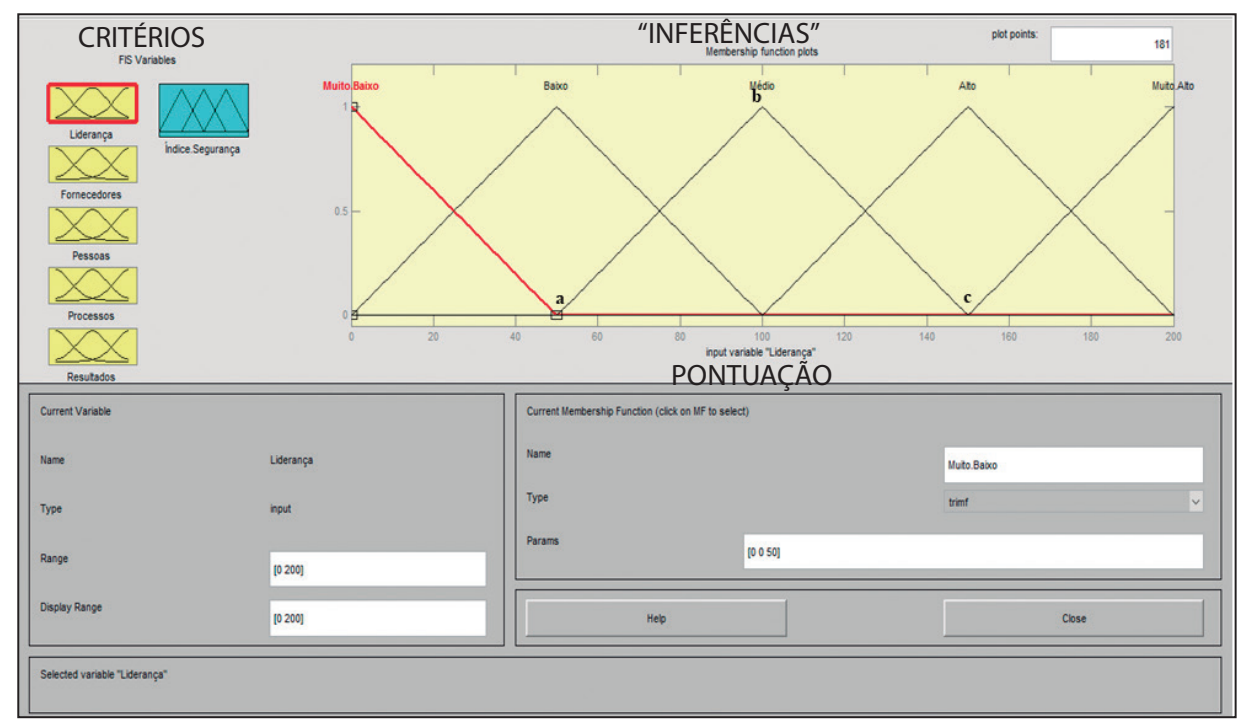

Fonte: Elaborada pelos autores. 
A Figura 5 demonstra o conjunto dos cinco outputs (1): Menção Honrosa; Bronze; Prata; Ouro e Excelência em Segurança, bem como os Critérios (2): Liderança; Fornecedores; Pessoas; Processos e Resultados. Em destaque (3) o Índice de Segurança e a Pontuação (4): 0 a 200. As funções de pertinência empregadas são triangulares, com equidistância entre as regiões de máxima pertinência aos conjuntos (ápices das funções triangulares), identificadas pelo numeral "1" no eixo das ordenadas. As interseções das funções triangulares representam a meia pertinência a cada conjunto adjacente, conforme indicam os valores " 0,5 ” no eixo vertical.

FIGURA 5

\section{Conjunto Fuzzy do output}

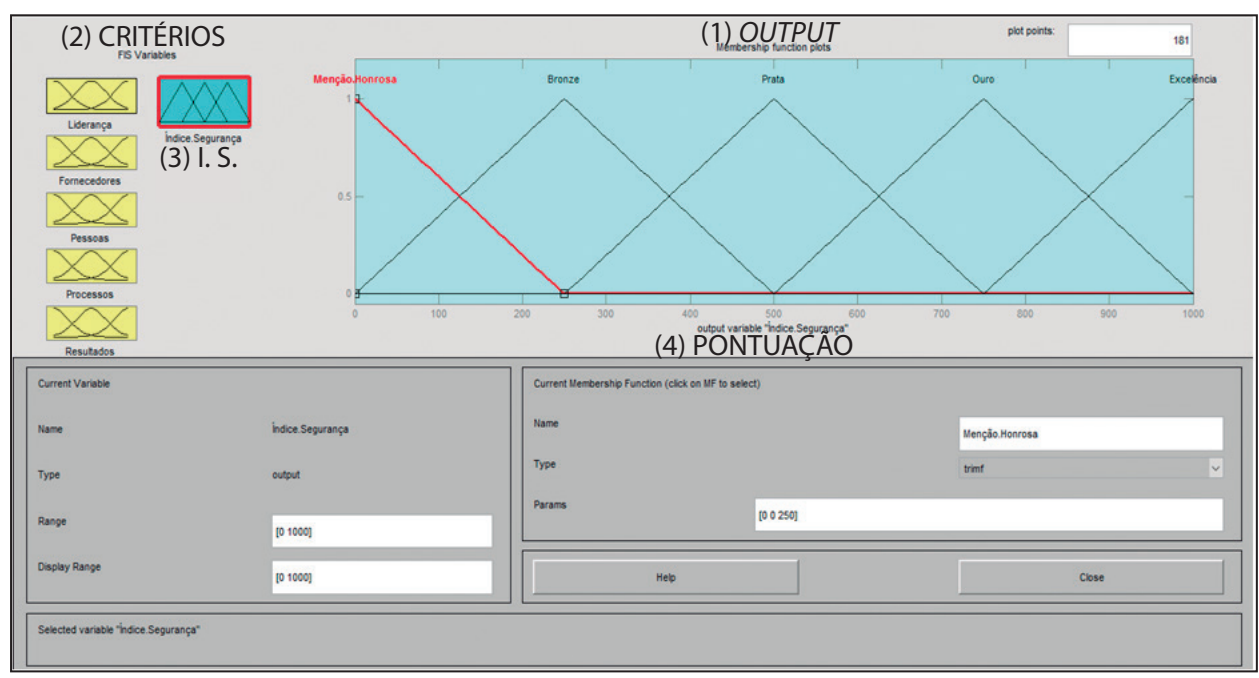

Fonte: Elaborada pelos autores.

Na segunda etapa foram desenvolvidas as Regras de "Inferência" do tipo "se-então", cuja finalidade é fazer com que o sistema Fuzzy produza as respectivas entradas e saídas, conforme mostra a Quadro 11.

\section{QUADRO 11}

\section{Regras de “Inferência" por Combs (1997)}

\begin{tabular}{|c|c|c|c|c|c|}
\hline \multicolumn{6}{|c|}{$\begin{array}{l}\text { REGRAS DE “TNFERÊNCIA", por Combs (1997): } \\
\text { - Agregação de regras por Combs } \\
\text { - Implicação dos Consequentes } \\
\text { - Agregação dos Resultados: Máximo }\end{array}$} \\
\hline & OU & OU & OU & OU & OU \\
\hline & $\downarrow$ & $\downarrow$ & $\downarrow$ & $\downarrow$ & $\downarrow$ \\
\hline Categoria & Iniciante & Bronze & Prata & Ouro & Excelência em Segurança \\
\hline CRITÉRIO 1 & Iniciante & Bronze & Prata & Ouro & Excelência em Segurança \\
\hline CRITÉRIO 2 & Iniciante & Bronze & Prata & Ouro & Excelência em Segurança \\
\hline CRITÉRIO 3 & Iniciante & Bronze & Prata & Ouro & Excelência em Segurança \\
\hline CRITÉRIO 4 & Iniciante & Bronze & Prata & Ouro & Excelência em Segurança \\
\hline CRITÉRIO 5 & Iniciante & Bronze & Prata & Ouro & Excelência em Segurança \\
\hline & $\downarrow$ & 7 & $\downarrow$ & 7 & $\downarrow$ \\
\hline & Regra & Regra & Regra & Regra & Regra \\
\hline & 1 & 2 & 3 & 4 & 5 \\
\hline
\end{tabular}

Fonte: Elaborada pelos autores. 
O número de regras de "inferência”, com a utilização do método URC, foi bastante reduzido, conforme a proposição de Combs (1997): 25 regras para os cinco SIF (apresentadas na Listagem 1).

\section{LISTAGEM 1}

Regras de inferência por Uniform Resource Classification

\section{REGRAS DE INFERÊNCIA, POR UNIFORM RESOURCE CLASSIFICATION (URC):}

1. If (Liderança is Muito.Baixo) then (Índice.Segurança is Iniciante) (1)

2. If (Fornecedores is Muito.Baixo) then (Índice.Segurança is Iniciante) (1)

3. If (Pessoas is Muito.Baixo) then (Índice.Segurança is Iniciante) (1)

4. If (Processos is Muito.Baixo) then (Índice.Segurança is Iniciante) (1)

5. If (Resultados is Muito.Baixo) then (Índice.Segurança is Iniciante) (1)

6. If (Liderança is Baixo) then (Índice.Segurança is Bronze) (1)

7. If (Fornecedores is Baixo) then (Índice.Segurança is Bronze) (1)

8. If (Pessoas is Baixo) then (Índice.Segurança is Bronze) (1)

9. If (Processos is Baixo) then (Índice.Segurança is Bronze) (1)

10. If (Resultados is Baixo) then (Índice.Segurança is Bronze) (1)

11. If (Liderança is Médio) then (Índice.Segurança is Prata) (1)

12. If (Fornecedores is Médio) then (Índice.Segurança is Prata) (1)

13. If (Pessoas is Médio) then (Índice.Segurança is Prata) (1)

14. If (Processos is Médio) then (Índice.Segurança is Prata) (1)

15. If (Resultados is Médio) then (Índice.Segurança is Prata) (1)

16. If (Liderança is Alto) then (Índice.Segurança is Ouro) (1)

17. If (Fornecedores is Alto) then (Índice.Segurança is Ouro) (1)

18. If (Pessoas is Alto) then (Índice.Segurança is Ouro) (1)

19. If (Processos is Alto) then (Índice.Segurança is Ouro) (1)

20. If (Resultados is Alto) then (Índice.Segurança is Ouro) (1)

21. If (Liderança is Muito,Alto) then (Índice.Segurança is Excelência) (1)

22. If (Fornecedores is Muito.Alto) then (Índice.Segurança is Excelência) (1)

23. If (Pessoas is Muito.Alto) then (Índice.Segurança is Excelência) (1)

24. If (Processos is Muito.Alto) then (Índice.Segurança is Excelência) (1)

25. If (Resultados is Muito.Alto) then (Índice.Segurança is Excelência) (1)

Fonte: Elaborada pelos autores.

\section{Experimento do Modelo Proposto}

Foi empregado na terceira fase, etapa 3.1, o software MatLab R2013a - Fuzzy Toolbox para a compilação do algoritmo de agregação dos indicadores. Assim, a Figura 6 apresenta o sistema Fuzzy desta pesquisa. A modelagem utilizou os operadores padronizados Min-Max da "inferência” tipo Mamdani, com "defuzificação" por centroide. O sistema foi desenvolvido no MatLab, versão Student R2013a, com a utilização do aplicativo gráfico Fuzzy Toolbox. 
O sistema apresenta cinco inputs e um output. Cada input possui amplitude no intervalo [0; 200] e o output em [0; 1000]. O input "Liderança" possui cinco perguntas que podem assumir pontuação entre [0; 40] e, no exemplo apresentado, teria recebido respostas “20", “18”, “5”, “17” e "33", totalizando "93" pontos. Esse procedimento repete-se nos demais inputs e o sistema Fuzzy efetua os cálculos do output. Os inputs e outputs são coletados com base nos protocolos de entrevistas constantes nos Quadros de 6 a 10.

\section{FIGURA 6}

Compilação do algoritmo de agregação dos indicadores

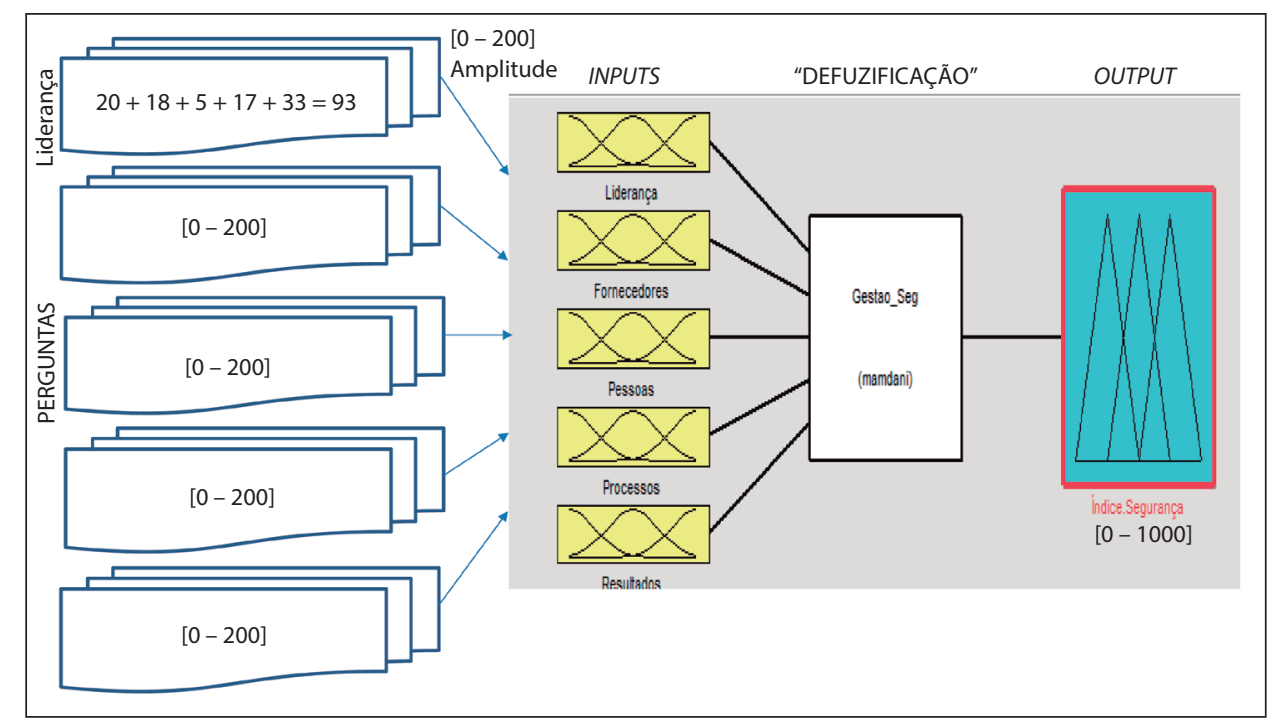

Fonte: Elaborada pelos autores.

A etapa 3.2, posteriormente, apresenta a simulação dos resultados em $3 \mathrm{D}$, que permite observar a análise do comportamento das variáveis, conforme a Figura 7 (Gráfico 3D), e ajustar os conjuntos Fuzzy e as regras de "inferência", de forma a expressar as características apresentadas pelos especialistas, durante a modelagem do problema.

\section{FIGURA7}

\section{Análise do comportamento das variáveis (Gráfico 3D)}

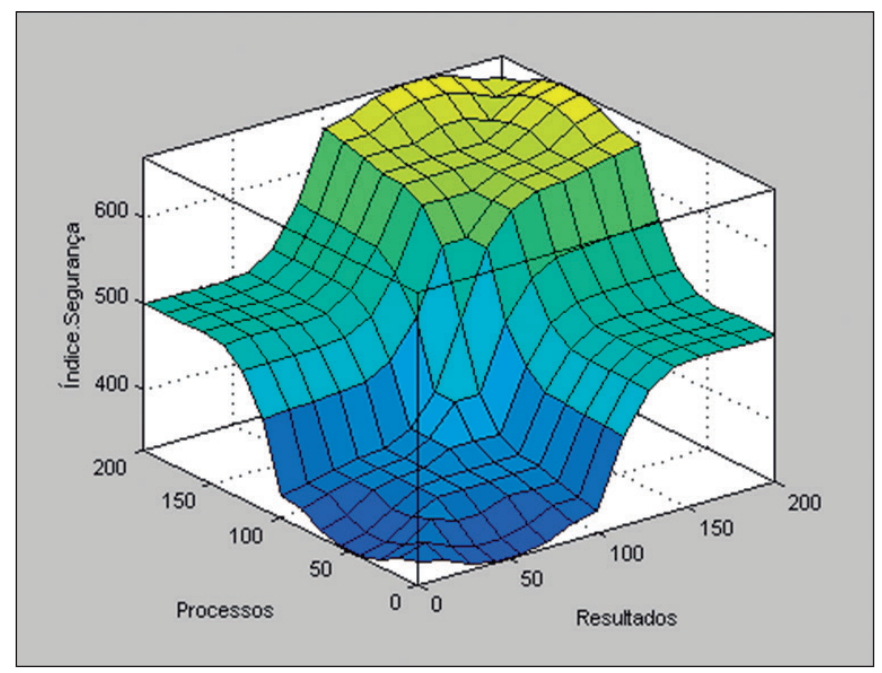

Fonte: Elaborada pelos autores. 


\section{Conclusão}

$\mathrm{Na}$ etapa 3.3, cumprindo o objetivo de estabelecer um modelo de mecanismos gerenciais de indicadores para a gestão de segurança de empresas de construção civil, baseado em programas nacionais de premiação e modelos de gestão, e corroborado pela aplicação dalógica Fuzzy, proposta pelo presente estudo, foi apresentada a síntese da estrutura de um Índice de Segurança com indicação Bronze para o sistema ora proposto de gestão, adequado às características de uma empresa hipotética de construção civil, que indica a necessidade de considerada melhoria aplicável em todos os processos da empresa auditada.

A importância deste sistema reside no fato de as empresas não utilizarem adequadamente o enorme potencial das informações oriundas dos prêmios de qualidade pesquisados, da aplicação da modelagem Fuzzy e do conhecimento dos especialistas que analisaram a empresa em experimento.

Pelo exposto, o presente trabalho oferece à Indústria da Construção Civil um instrumento de melhoria eficiente, eficaz, de baixo custo e de fácil aplicação. Os resultados obtidos têm por finalidade avaliar o desempenho, assim como a eficiência do sistema de gestão com o apoio da lógica nebulosa. 


\section{Referências}

ALMEIDA, A. C. et al. (Coord). Compreendendo a Responsabilidade Social: ISO 26000 e ABNT NBR 16001. Brasília, DF: Ministério do Meio Ambiente, 2015. Disponível em: <http://www.inmetro.gov.br/ qualidade/responsabilidade_social/cartilha.asp>. Acesso em: 08 mar. 2016.

BRASIL. Decreto n 8.373 , de 11 de dezembrode 2014. Institui o Sistema de Escrituração Digital das Obrigações Fiscais, Previdenciárias e Trabalhistas - eSocial e dá outras providências. Diário Oficial, Brasília, DF, 12 dez. 2014. Disponível em: <http://www.planalto.gov.br/ccivil_03/_Ato2011-2014/2014/Decreto/D8373. htm>. Acesso em: 10 dez. 2015.

BRASIL. Decreto-Lei no 5442, de $1^{\circ}$ de maio de 1943. Aprova a Consolidação das Leis do Trabalho. Diário Oficial da República Federativa do Brasil: seção I, parte I, Rio de Janeiro, p. 11937, 09 ago. 1943. Disponível em: <http://www2.camara.leg.br/legin/fed/declei/1940-1949/decreto-lei-5452-1-maio-1943415500-norma-pe.html>. Acesso em: 22 maio 2016.

BRASIL. Ministério do Trabalho e da Previdência Social. Informe da Previdência Social. 2014. Disponível em: <http://www.previdencia.gov.br/wp-content/uploads/2014/10/Ret _Offset_Informe_ julho_2014.pdf>. Acesso em: 17 dez. 2015.

BRASIL. Portaria no 3.214, de 8 de junho de 1978. Aprova as Normas Regulamentadoras - NR - do Capítulo V, Título II, da Consolidação das Leis do Trabalho, relativas a Segurança e Medicina do Trabalho. Diário Oficial da União: seção I, parte I, Brasília, DF, n. 127, p. 10.243, 06 jul. 1978. Disponível em: <http://www.editoramagister.com/doc_308880_PORTARIA_N_3214_DE_8_DE_JUNHO_DE_1978. aspx>. Acesso em: 14 abr. 2016.

BRASIL. Secretaria da Receita Federal do Brasil. Ministério da Fazenda. Já está no ar o eSocial para o Empregador Doméstico. 2015. Disponível em: <http://idg.receita.fazenda.gov.br/noticias/ascom/2015/ outubro/ja-esta-no-ar-o-esocial-para-o-empregador-domestico>. Acesso em: 10 dez. 2015.

CARNEIRO, S. Q. Contribuições para a integração dos sistemas de gestão ambiental, de segurança e saúde no trabalho, e da qualidade, em pequenas e médias empresas de construção civil. 2005. 169 f. Dissertação (Mestrado em Engenharia Ambiental Urbana) - Universidade Federal da Bahia, Salvador, 2005. Disponível em: <http://repositorio.ufba.br:8080/ri/bitstream/ri/9983/1/S\%C3\%A9rgio.pdf >. Acesso em: 16 abr. 2015.

COMBS, W. E. The Combs Method For Rapid Inference. Seattle: The Boeing Company, 1997. Disponível em: <http://athena.ecs.csus.edu/ hellerm/EEE222/Atricles/Combs_Fuzzy_Logic/Combs_Rapid_Inference. htm>. Acesso em: 06 jun. 2014.

COX, E. Fuzzy logic for business and industry. Massachusetts: Charles River Media INC, 1995.

COX, E. Fuzzy systems handbook: a practioner's guide to building, using, and maintaining fuzzy systems. 2. ed. New York: Academic Press, 1999.

DANNENBERG, L. C.; SIMURRO, S. (Coord.). Manual de Participação do XVIII Prêmio Nacional de Qualidade de Vida da ABQV. São Paulo: ABQV, 2015. Disponível em: < https://docplayer.com.br/12292015Xviii-premio-nacional-de-qualidade-de-vida-da-abqv-pnqv-ciclo-2015.html>. Acesso em: 31 out. 2015.

DUARTE, C. M. de M.; LORDSLEEM JÚNIOR, A. C. Indicadores de desempenho de empresas construtoras com certificação ISO 9001 e PBQP-H. In: SIMPÓSIO BRASILEIRO DE GESTÃO E ECONOMIA DA CONSTRUÇÃO, 6., Campinas, 2009. Anais... Campinas: SIBRAGEC, 2009. Disponível em: <https://docplayer.com.br/6594252-Indicadores-de-desempenho-de-empresas-construtoras-comcertificacao-iso-9001-e-pbqp-h.html>. Acesso em: 16 abr. 2015. 
FUNDAÇÃO JORGE DUPRAT FIGUEIREDO DE SEGURANÇA E MEDICINA DO TRABALHO - FUNDACENTRO. De olho nas Olimpíadas, instituições assinam protocolo para a redução dos acidentes em megaobras. 2015. Disponível em: <http://www.fundacentro.gov.br/noticias/detalhe-danoticia/2015/3/de-olho-nas-olimpiadas-instituicoes-assinam-protocolo-para-a-reducao-dos-acidentesem-grandes>. Acesso em: 14 abr. 2016.

FUNDAÇÃO NACIONAL DA QUALIDADE - FNQ. Critérios de excelência: avaliação e diagnóstico da gestão organizacional. 20. ed. São Paulo: FNQ, 2013.

GAVIÃO, L. O.; LIMA, G. B. A. Diagnóstico Multidisciplinar da Educação Ambiental no Ensino Médio Brasileiro: aplicação de indicadores de desempenho em uma escola de Niterói (RJ). Ensino, Saúde e Ambiente, v. 7, n. 2, p. 46-63, ago. 2014. Disponível em: <http://periodicos.uff.br/ensinosaudeambiente_ backup/article/viewFile/14689/9290>. Acesso em: 14 abr. 2015.

GORDONO, F. S. et al. Implantação da OSHAS 18001: um estudo de caso de uma empresa construtora da cidade de Bauru, SP. In: CONGRESSO NACIONAL DE EXCELÊNCIA EM GESTÃO, 8., Rio de Janeiro. 2012. Anais... Rio de Janeiro: INOVARSE, 2012. Disponível em: <http://www.inovarse.org/filebrowser/ download/15866>. Acesso em: 13 jun. 2016.

JANÉ, D. A. Uma Introdução ao Estudo da Lógica Fuzzy. Hórus - Revista de Humanidades e Ciências Sociais Aplicadas, Ourinho, v. 1, n. 2, 2004. Disponível em: <http://docplayer.com.br/48330821-Umaintroducao-ao-estudo-da-logica-fuzzy-an-introduction-to-fuzzy-logic.html>. Acesso em: 04 jan. 2016.

KLIR, G. J.; YUAN, B. Fuzzy sets and fuzzy logic: theory and applications. New Jersey: Prentice Hall. 1995.

MARTINS, O. et al. Responsabilidade social empresarial: o processo de institucionalização em uma empresa ganhadora do prêmio SESI de qualidade no trabalho. Revista Portuguesa e Brasileira de Gestão, v. 12, n. 2, p. 75-87. 2013. Disponível em: <http://www.redalyc.org/pdf/3885/388539137007. pdf>. Acesso em: 04 ago. 2016.

MOREIRA, D. J. O planejamento estratégico na prevenção de acidentes no trabalho: todos saem ganhando. 2015. Disponível em: <https://jus.com.br/artigos/34194/o-planejamento-estrategico-naprevencao-de-acidentes-no-trabalho-todos-saem-ganhando>. Acesso em: 02 fev. 2016.

NUNES, T. A. Aplicabilidade da NR 18 em canteiros de obras - Estudos de caso em obras na Cidade de Santa Maria/RS. 2016. Monografia (Bacharel em Engenharia Civil) - Universidade Federal de Santa Maria, Santa Maria, 2016. Disponível em: <http://coral.ufsm.br/engcivil/images/PDF/1_2016/TCC_ THAIS\%20ANTUZA\%20NUNES.pdf>. Acesso em: 13 jun. 2016.

O QUADRO da insegurança no trabalho. O Globo, Rio de Janeiro, 21 maio 2015. Disponível em: <http:// infograficos.oglobo.globo.com/economia/o-quadro-da-inseguranca-no-trabalho.html>. Acesso em: 23 abr. 2016.

OHSAS 18001. Sistemas de Gestão da Segurança e da Saúde do Trabalho: requisitos. 2007. Disponível em: <https://comum.rcaap.pt/bitstream/10400.26/7319/2/Anexo\%20I\%20OHSAS180012007_pt.pdf>. Acesso em: 24 jan. 2016.

OLIVEIRA, G. T.; MARTINS, R. A. Efeitos da adoção do modelo do Prêmio Nacional da Qualidade na medição de desempenho: estudos de caso em empresas ganhadoras do prêmio. Gestão \& Produção, v. 15, n. 2, p. 247-259, 2008. Disponível em: <http://www.scielo.br/pdf/gp/v15n2/a04v15n2>. Acesso em: 15 ago. 2016. 
ROSS, T. J. Fuzzy Logic with engineering applications. 3. ed. New Jersey: Wiley, 2010. Disponível em: <http://ruangbacafmipa.staff.ub.ac.id/files/2012/02/ebooksclub.org_Fuzzy_Logic_with_Engineering_ Applications_Third_Edition.pdf >. Acesso em: 02 fev. 2015.

SANTANA, V. S. (Org.). Segurança e saúde na Indústria da construção no Brasil: diagnóstico e recomendações para a prevenção dos acidentes de trabalho. Brasília: SESI/DN, 2012. Disponível em: <https://www.ufrgs.br/cedop/wp-content/uploads/2013/05/Seguran\%C3\%A7a_e_sa\%C3\%BAde_na_ contru\%C3\%A7\%C3\%A3o_civil_Jan13.pdf>. Acesso em: 19 abr. 2016.

SANTOS, M. T. et al. Identificação de práticas de responsabilidade socioambiental em duas empresas: uma análise baseada no modelo de gestão do Prêmio Nacional da Qualidade. Revista Exacta, v. 12, n. 1, p. 13-32, 2014. Disponível em: <http://www.redalyc.org/pdf/810/81031548002.pdf>. Acesso em: 20 jan. 2015.

SEGUNDO, C. C. A.; SOUZA, E. A nova ISO 45001:2016 e suas Contribuições. In: SIMPÓSIO DE EXCELÊNCIA EM GESTÃO E TECNOLOGIA, 12., Resende, 2015. Anais... Resende: AEDB, 2015. Disponível em: <http://www.aedb.br/seget/arquivos/artigos15/38922442.pdf>. Acesso em: 22 maio 2016.

TAKAHASHI, H. et al. The SAGA histone acetyltransferase complex regulates leucine uptake through the Agp3 permease in fission yeast. Journal of Biological Chemistry, v. 287, n. 45, p. 38158-67, 2012.

TODESCHINI, R. PL 4330: Terceirização agrava acidentalidade em atividades fins e meio. Confederação Nacional do Ramo Químico, São Paulo, 07 maio 2015. Disponível em: <http://cnq.org.br/artigos/pl4330-terceirizacao-agrava-acidentalidade-em-atividades-fins-e-meio-3db4/>. Acesso em: 04 ago. 2015.

ALOISIO CELSO DE ARAUJO

ORCID: https://orcid.org/0000-0003-1510-5449

Especialista em Segurança do Trabalho na Universidade Federal Fluminense (UFF); Mestrando em Engenharia Civil pela Universidade Federal Fluminense (UFF), Niterói - RJ, Brasil.

E-mail: aloisiocelso.mec.uff@gmail.com

JOÃO ALBERTO NEVES DOS SANTOS

ORCID: https://orcid.org/0000-0002-4812-6214

Doutor em Engenharia de Produção pela Pontifícia Universidade Católica do Rio de Janeiro (PUC-Rio); Professor Adjunto da Universidade Federal Fluminense (UFF), Niterói - RJ, Brasil.

E-mail: joaoalbertoneves@gmail.com

\section{GILSON BRITO ALVES LIMA}

ORCID: https://orcid.org/0000-0001-6741-2403

Doutor em Engenharia de Produção pela Universidade Federal do Rio de Janeiro (UFRJ); Mestre em Engenharia Civil pela Universidade Federal Fluminense (UFF); Especialista em Segurança do Trabalho pela Universidade Federal Fluminense (UFF), Niterói - RJ, Brasil. E-mail: glima@id.uff.br

\section{JULIO NICHIOKA}

ORCID: https://orcid.org/0000-0003-0070-6508

Doutor em Engenharia Civil pela Universidade Federal Fluminense (UFF); Mestre em Engenharia de Produção pela Universidade Federal do Rio de Janeiro (UFRJ); Especialista em Engenharia de Segurança do Trabalho pela Faculdade Integrada Silva e Souza, Rio de Janeiro - RJ, Brasil. E-mail: jnichioka@oi.com.br

\section{LUIZ OCTÁVIO GAVIÃO}

ORCID: https://orcid.org/0000-0003-3580-7085

Professor Adjunto do Centro de Capacitação em Aquisição de Defesa (CCAD) da Escola Superior de Guerra (ESG); Mestrado em Estudos Militares na Universidade do Corpo de Fuzileiros Navais dos EUA; Mestrado em Engenharia de Produção pela Universidade Federal Fluminense (UFF); Doutor em Engenharia de Produção na Universidade Federal Fluminense (UFF), Rio de Janeiro - RJ, Brasil.

E-mail: luiz.gaviao67@gmail.com 